\title{
LEGALIZAÇÃO DAS DROGAS ILÍCITAS NO BRASIL
}

Leila Bijos ${ }^{1}$

\section{RESUMO:}

A presente pesquisa consiste em apontar a perspectiva da legalização do consumo das drogas no Brasil, a partir de influências recebidas de políticas internacionais, encampadas pelos países vizinhos da América Latina. Em face da estigmatização que ronda o assunto, a pesquisa em pauta analisa a ausência de dados precisos sobre as razões que levaram países em desenvolvimento, com níveis de pobreza extrema, a flexibilizar o consumo de drogas ilícitas na contemporaneidade. A legalização dos entorpecentes gera um custo substantivo para a segurança pública, afeta o desempenho laboral dos cidadãos, desestrutura a base familiar, causa problemas físicos e mentais, em todas as classes sociais. A partir de uma pesquisa empírica, indaga-se a respeito do contexto histórico do surgimento das drogas, sua produção, localização e, principalmente, público consumidor. A globalização se apresenta em âmbitos positivos, com desenvolvimento econômico, novas tecnologias da inovação, mas com vieses legislativos que perpassam pela política de drogas e a Política Nacional de Saúde Mental, que disciplina a atenção a usuários e dependentes no SUS (Sistema Único de Saúde), proibindo o uso de tratamentos com substâncias ilícitas, afetando a vida de pessoas portadoras de doenças que dependem desses medicamentos. No entanto, discutem-se os reflexos das tomadas de decisão em razão da descriminalização de drogas, como o álcool e o fumo em escala global, bem como drogas entorpecentes num cenário lendário de chefes do narcotráfico na Colômbia, Estados Unidos da América, Europa e Ásia.

Palavras-Chave: Descriminalização de drogas; Segurança Pública e Saúde; Política Internacional; Direito Econômico.

\section{THE LEGALIZATION OF ILLICIT DRUGS CONSUMPTION IN BRAZIL}

\begin{abstract}
The main objective of this research is to point out the perspective about the legalization of illicit drugs consumption in Brazil, based on international policies implemented by nearby countries in Latin America. Due to the stigma that surrounds the subject, this

\footnotetext{
${ }^{1}$ Pós-Doutora pela Saint Mary's University, Halifax, Nova Scotia, Canadá. Doutora em Sociologia do Desenvolvimento, CEPPAC/UnB. Possui cursos de Especialização em Direitos Humanos no IIDH, San José/Costa Rica, UN Genebra/Suíça, IIDH, Strasbourg/França. Professora Adjunta do Departamento de Sociologia e Criminologia, Saint Mary's University, Halifax, Nova Scotia, Canadá (2015/2018). Professora Adjunta do Mestrado Stricto Sensu em Direito Econômico Internacional da Universidade Católica de Brasília. Coordenadora do Grupo de Pesquisa "Laboratório de Política Internacional", e da Linha de Pesquisa em Direitos Humanos. É membro da Cátedra da UNESCO de Juventude, Educação e Sociedade. Autora de livros, capítulos de livros, e mais de cinquenta estudos e ensaios sobre política internacional, políticas públicas e sociais, direitos humanos, e questões migratórias. Pesquisadora Visitante da Universidade de Hyderabad, Índia; do Programa de Doutorado em Economia Internacional da Universidade de Tsukuba, e da University of Califórnia, San Diego (UCSD). Participou de vários cursos de Política Internacional nos EUA, Suíça, Taiwan, Israel, dentre outros. Fluente em inglês, francês, e espanhol.
} 
research aims to present the lack of information that made developing countries, with high poverty levels, to allow illicit drugs consumption in the contemporaneity. The legalization of illicit drugs creates a substantial cost to public security and drugs affect the work performance of people, causing physical and mental problems. From an empirical research, it inquires about the historical context of the emergence of drugs, its production, location and, mainly, consumer public. Globalization presents itself in positive environments, with economic development, new technologies of innovation, but with legislative biases that go through the drug policy and the National Policy of Mental Health, which disciplines the attention to users and dependents in the Unified Health System (SUS), prohibiting the use of treatments with illicit substances, affecting the life of people with diseases that depend on these drugs. However, the effects of drug decriminalization, such as alcohol and tobacco on a global scale, as well as narcotic drugs in a legendary scenario of drug traffickers in Colombia, The subject is considered an empirical methodology based on qualitative data, supported by legal frameworks which present the consequences of legalizing illicit drugs and the effect on people's life. Key-words: Drug decriminalization; Public Security and Health; International Policy; Economic Law.

\section{INTRODUÇÃO}

A globalização se apresenta como um cenário de relevantes avanços, na área tecnológica, em padrões de conhecimento, níveis de riqueza, e bem-estar social para a sociedade, assim como trocas comerciais e acesso às drogas ilícitas.

O mundo globalizado, na fase atual da economia mundial, divide-se em países desenvolvidos e em desenvolvimento, com nichos de riqueza e bem-estar social; e áreas periféricas, onde grassa a pobreza endêmica, num contexto abrangente de assimetrias econômicas, estruturais e morais, que afetam a liberdade e a inserção cidadã no mercado de trabalho, com consequências nefastas nos níveis de transparência governamental.

A disparidade de renda, como marca do sistema econômico predominante, num contexto de liberalismo, apresenta linhas de debate acerca das mudanças políticas e sociais, dentre elas a Lei de Drogas, que instituiu em 2006 uma política nacional sobre drogas. O objetivo da Lei de Drogas era instituir um sistema de orientação aos Estados e a integração de suas políticas públicas. A grande novidade trazida pela lei, que substituiu a anterior, de 1976 (Lei 6.368), foi distinguir a maneira de lidar com usuários e traficantes.

O tema é polêmico, uma vez que o uso das drogas ilícitas, não pode ser enfrentado isoladamente, pois depende da construção de uma rede de intercooperação internacional, fundada no Direito Internacional, visando respeitar não só os Direitos Humanos, mas também a soberania dos entes envolvidos.

No que se refere à América Latina, o histórico cultural destes países revela uma colonização de exploração, do uso de recursos, em detrimento dos povos que habitavam o continente, que sofreram com a escravidão, e desvalorização de seu potencial humano.

Tentativas de cooperação nas últimas décadas, se viram frustradas devido a diferenças ideológicas dominantes de cada país, alguns com governos conservadores outros liberais, bem como outras formas de disputas políticas, econômicas ou territoriais. Portanto, é chegado o momento de reanalisar este passado de insucesso, uma vez que o crime organizado tem evoluído e utilizado variadas formas de subterfúgios, que propiciam a propagação do mercado de drogas, lavagem de dinheiro e tráfico de pessoas. 
Ações isoladas de enfrentamento ao narcotráfico incluem a erradicação de plantações, a interdição de rotas de passagem, o combate a organizações criminosas, que afastam temporariamente de cena os atores criminosos. Esses grupos mafiosos são reprimidos pelas autoridades estatais, mas se reorganizam, estruturam novos espaços de atividades, ora migrando o local das plantações de uma região para outra, ora alterando as rotas e pontos de apoio de transporte dos produtos ilícitos.

A partir da abertura das fronteiras, e a ausência de documentação para entrada nos países membros do Mercosul, o que propiciou a mobilidade no trânsito de pessoas, e comercialização efetiva de mercadorias entre os países do Bloco. Intensificou-se o número de organizações criminosas, sempre dispostas a alterar a logística operacional a fim de driblar os meios de fiscalização.

Nesse diapasão, cumpre analisar a diversidade de características do usuário de drogas, seu envolvimento com o narcotráfico, e as consequências dessas ações ilícitas.

Como objetivo, tende-se a demonstrar os reflexos da descriminalização do uso de substâncias entorpecentes ilícitas em um contexto contemporâneo influenciado pela política internacional e a influência dos países que efetivaram as medidas legais ao uso de determinadas substâncias.

\section{DROGA PSICOATIVA}

De acordo com uma conjuntura histórica as substâncias psicoativas foram utilizadas para diferentes finalidades, inclusive cultos religiosos. Na década de 1960, com o surgimento do comércio das drogas, a difusão de negócios, e implicações politicas, verificou-se o aumento de doenças transmissíveis, parte de uma engrenagem de dependentes, que deveriam ser reavaliados num contexto biopsicossocial, como usuários de drogas. As drogas não se restringem a drogas vegetais, mas, também ao álcool, que é considerado a droga mais antiga do mundo, que muda o comportamento do usuário.

Na década de 1970 o uso nocivo das drogas e suas dependências, tomou proporção crescente. O sintético, metadona, meperidina, petidina, e o semi-sintético, a heroína tomaram espaço na sociedade. A cocaína é uma droga que originou vários subprodutos, a pasta de coca, crack, e a merla que podem ser cheirados, injetados ou fumados são alguns exemplos. No século XIX, o comércio e o uso da cocaína foram considerados um "problema social", associados à degeneração psíquica, crime e à marginalização. Estatísticas oficiais apresentadas pelo Ministério da Saúde apontaram que, no Brasil em 1997, era a droga mais usada por estudantes do ensino fundamental e do ensino médio (MACRAE, 2003).

\subsection{CARACTERÍSTICAS DAS DROGAS ILÍCITAS}

As drogas ilícitas são substâncias proibidas de serem produzidas, comercializadas e consumidas. Nenhuma das substâncias listadas na portaria, n. ${ }^{\circ}$ 344, de 12 de maio de 1998, tem utilidade como medicamento, na qual são atualizadas constantemente outras substancias que simulam efeitos semelhantes ao de drogas ilícitas já conhecidas e listadas na portaria $n^{\circ} 344$ da ANVISA (2014), como ópio, heroína e LSD, que agem sobre o sistema nervoso central e podem provocar alucinações.

Em alguns países, a exemplo: Uruguai, Argentina, Bolívia, Chile, Costa Rica, Jamaica, Estados Unidos da América, Holanda, Alemanha, determinadas drogas são permitidas sendo que seu uso é considerado normal e integrante da cultura 
(LEONARDO, 2015). Tais substâncias podem ser estimulantes, depressivas ou perturbadoras do sistema nervoso central, o que perceptivelmente altera em grande escala o organismo (CRUZ, 2016).

Atualmente são drogas ilícitas: cocaína, maconha, inalantes, LSD, ecstasy, crack, chá de cogumelo, skank, morfina, barbitúricos, clorofórmio, anfetaminas, heroína, ópio entre outras. Evidentemente e por serem proibidas, as drogas ilícitas entram no país, ou são produzidas para comercialização de forma ilegal. Dentre as consequências que as drogas ilícitas trazem pode-se dar ênfase à violência gerada por elas em todas as fases de produção até o consumidor final. A característica do uso das drogas são severas aos usuários: arritmia cardíaca, trombose, AVC, necrose cerebral, insuficiência renal e cardíaca, depressão, disforia, alterações nas funções motoras, perda de memória, disfunções no sistema reprodutor e respiratório, câncer, acnes, convulsões, desidratação, náuseas e exaustão (ABEAD, 2006).

É importante esclarecer que essas drogas com restrição de comercialização determinada pela ANVISA, geram dependência, apesar de recentes decisões judiciais, que permitem seu uso como tratamento médico, contrariando a portaria. A dependência química é tratável, ou seja, através do auxílio médico, com apoio familiar, a fim de rever e deixar o vício e voltar ao convívio social sem os efeitos das drogas.

\section{O PAPEL DAS AGÊNCIAS GOVERNAMENTAIS NO CONTROLE E REPRESSÃO}

Novas estratégias de desenvolvimento sanitário implicam na regulação de políticas nas quais a segurança dos medicamentos seja o elemento preponderante. Neste contexto, existem órgãos de registro de medicamentos, tanto nacional quanto internacional, evitando-se, assim os grupos criminosos, que operam em zonas produtoras, subornam as autoridades, e espalham seus tentáculos para as mais remotas áreas do globo, com lucros de até 50\% no total das vendas (GONZALEZ, 2015).

As coalizações internacionais devem ser fundamentadas na conjugação de ações e compromissos de Estados nacionais para evitar a proliferação das drogas, do contrabando, da lavagem de dinheiro, e dos carteis internacionais de drogas. Desentendimentos internacionais e omissão das autoridades nesse sentido significa promover os negócios ilícitos, denunciando a fragilidade ao combate, tráfico e erradicação de sistemas de substâncias ilícitas, que prejudicam a saúde e a integridade dos cidadãos. O combate aos ilícitos precisa ser combatido por normas jurídicas homogêneas.

Ao investigar-se o Brasil e seus meandros políticos e econômicos, adentra-se no controle sanitário nacional, que aponta uma extensa lista de substâncias, que de acordo com a ANVISA - Agência Nacional de Vigilância Sanitária (2014) são substâncias taxadas como entorpecentes, temas que assolam o tráfico, e faz parte da chamada Lei de Tóxicos, tratada desde 1976, como Lei 6.368. Esse banco de dados promovido por essa autarquia é constantemente atualizado, com dados de drogas que escondem riscos maiores à saúde, por sua vez, seus efeitos irreversíveis, alastrando surtos psicóticos, alucinações e danos cerebrais que podem acarretar a morte (NEUMAN, 2008). Um desafio que estende a toda sociedade, projetando sofrimento sem precedentes àqueles que são dependentes, considerada preocupante a situação, uma problemática que compromete a saúde pública (VIDALE, 2017).

É evidente que existem falhas na postura das restrições, tendo em vista que algumas drogas e consumo são irrestritos, tais como o álcool e o tabaco, a aceitação 
dessas drogas gera precedente para outras drogas. Alguns países adotam a legalização do consumo das drogas ilícitas, outros flexibilizam o consumo para usuários. De fato é uma tendência a ser respeitada por outros países. Evidentemente que manter resistência gera um custo elevadíssimo aos órgãos públicos nacionais, no entanto, novas drogas surgem prejudicando o controle das Agências (CRUZ, 2016).

O crescimento do consumo de drogas ilícitas acelera cada vez mais em um contexto mundial, os números impressionam o sistema de segurança e a rede de saúde pública, o que acarreta envolvimento de uma estrutura organizada no tráfico de drogas. O impacto é refletido na saúde pública, no desvio de verbas que poderiam ser concentradas na educação, na saúde, nos investimentos habitacionais, e na infraestrutura pública (ABEAD, 2006). Nessa perspectiva, não há homogeneidade na plataforma de combate às drogas, quando se tema perpassa pelas fronteiras nacionais e avança pelos países fronteiriços ao Brasil, o que propõe mais trabalho, e consequentemente constantes atualizações nos dados de informações das Agências reguladoras, assim como na cooperação internacional com agências especializadas das Nações Unidas e Organizações Não-Governamentais.

\section{A LEGALIZAÇÃO INTERNACIONAL DAS DROGAS ILÍCITAS}

O impacto das atividades de tráfico internacional de drogas constata a necessidade de novos procedimentos para a segurança internacional, uma vez que não existem mais barreiras entre os países para os traficantes, gerando ataques às nações, desestabilizando os sistemas, e órgãos governamentais gerando insegurança internacional.

Kissinger (2001) infere acerca do comércio de drogas na China, as consequências para o país, e para os cidadãos, e quais reformas se fizeram necessárias para debelar o consumo de ópio, proteger a segurança de população chinesa, e voltar o país para aspirações internacionais mais avançadas, reivindicando um novo reconhecimento internacional e, a reconstrução política. Compreender tanto a história como o passado da nação mostra a influência de um país no mundo Global.

O modelo econômico e social que roga em toda a América Latina um número expressivo de usuários envolvidos com entorpecentes é inaceitável do ponto de vista moral e religioso. É um problema de ordem política social e suas consequências são negativas para o desenvolvimento sustentável do país, com reflexo internacional. $\mathrm{O}$ tráfico assumiu novas dimensões como modeladora do social e do cultural em muitos países. Está ligado a todas as classes sociais e impulsiona empresas a se envolve em negócios ilícitos. Como chamar a atenção da comunidade internacional para as comercializações de entorpecentes se o tráfico movimenta anualmente, com a cocaína, bilhões de dólares? (DIJO; MAIEROVITCH, 2010)

Em outro contexto, verifica-se que o tráfico de entorpecentes encontra-se ligado ao tráfico de armas, que inundou o mercado internacional, o tráfico de armas supre o narcotráfico na defesa de seus interesses (ABEAD, 2006).

Os negócios de tráfico de drogas sofreram um grande impulso a partir da década de 1990, resultantes da exacerbação do neoliberalismo, com a abertura indiscriminada dos mercados, a desregulamentação financeira internacional, que expulsou os trabalhadores formais de seus empregos.

Dentre os fatores negativos sobressai-se a instabilidade política em diversos países, dificultando as negociações e o bom entendimento entre os governantes (BIJOS, 2010). 
A estrutura do tráfico internacional é sustentada através de usuários que utilizam de forma descontrolada a produção de cocaína, maconha, merla, e outras drogas sintéticas, atingindo lucros exorbitantes de mais de 70 bilhões de dólares (GONZALEZ, 2015). Tendo em vista a impossibilidade de controlar e promover a fiscalização direta e efetiva em âmbito internacional, tratados internacionais são firmados para inibir a modulação de projetos que se estruturam, impedindo que se fortaleçam e ampliem seus mercados de consumidores. Para diagnosticar e manter dados estatísticos reais, catalogando a quantidade de usuário, não resta alternativa, a não ser adotar uma política de legalização da droga, o que levanta inúmeras polêmicas.

Num primeiro momento são necessárias informações jurídicas que avaliem a o projeto de uma nova Lei de Drogas, em análise comparativa ao que foi proposto pelo Senado em 2002, em face de uma onda de "sequestros relâmpagos", que provocou uma grande comoção na comunidade, e aumentou consideravelmente o clima de insegurança em todo o país. Essa nova lei poderá ser utilizada para controlar e combater o consumo de entorpecentes, imunizar o Estado de recursos vultosos, dispensar menos contingentes de repressão e coletar número maior de informações que poderão ser inclusive utilizadas para combater o tráfico internacional de drogas ilícitas (SANTOS, 2010). Diante de uma política discriminadora por países vizinhos torna insustentável impedir a infiltração de drogas ilícitas. Faz-se mister, nesse contexto, implementar um debate institucional, de avaliação dos aspectos positivos da descriminalização, visando à influenciar países vizinhos no Cone Sul, para que apoiem as mudanças no Brasil, e possam optar pela mesma decisão.

\subsection{FORTALECIMENTO DO ORDENAMENTO JURÍDICO}

Propiciar o fortalecimento do ordenamento jurídico significa organizar o poder do Estado Nacional, portando, combater o tráfico, de forma a capacitar os gestores públicos, fornecendo meios para enfrentar novas situações que reverberem em nível internacional.

As coalizações internacionais jurídicas são conjugadas em compromissos de Estados nacionais para evitar a deterioração da sociedade e a estagnação da economia.

Nesse contexto, ressalte-se, como desafiador para o sistema judiciário a implementação de ações efetivas de repreensão ao tráfico, já que há dezenas de processos no STF (Supremo Tribunal Federal) pendentes de uma legislação que corresponda à realidade sobre a descriminalização do porte de drogas para consumo próprio (SOARES, 2011).

Se aprovada essa medida, será um precedente, para aumentar o poder de decisão dos juízes de primeiro grau diante dos flagrantes. Embora por lei apenas o traficante possa ser mantido preso, quem decide se o individuo será enquadrado na condição de usuário ou traficante é o magistrado, valorizando a trajetória dos fatos e as diversidades de provas.

Juridicamente, é punido com pena de prisão de 5 a 15 anos importar, exportar e guardar drogas, além de cultivar matéria-prima para o tráfico, o que acarreta a mesma penalidade. Dispositivos anteriores à Lei de Drogas, como a Constituição e a Lei de Crimes Hediondos, estabelecem que os condenados por tráfico não podem ser beneficiados com a extinção de suas penas (anistia, graça ou indulto). A questão colocada pela legislação atual é: como diferenciar um usuário de um traficante? A redação da Lei de Drogas recorre a critérios subjetivos, o que, na prática, deixa nas mãos de cada juiz decidir quem é enquadrado em qual categoria. 
O que se percebe nos países que já descriminalizaram o uso das drogas, é que se reduziu a morosidade em promover e resolver o processo em juízo, isso inclui os países da América Latina, aonde o Brasil chega tarde ao que diz respeito aos estudos de descriminalização das drogas.

No entanto, em comparação com o sistema judiciário de outros países, como os da África e vários da Ásia, o fato de o caso ter chegado ao Supremo é um fator indicativo que o Brasil está bastante adiantado no debate, isto porque as discussões podem apreciar experiências práticas de outros países (LEONARDO, 2015).

Alguns dos países, como o Uruguai, que adotou a postura de regulamentar todo o ciclo de consumo da maconha, deixando-o sob o controle do Estado. A postura deste país foi adotar que os maiores de 18 anos podem comprar e cultivar a erva legalmente na condição de prévio cadastro controlado pelo Estado.

Num outro diapasão, a Argentina, em 2009, também cedeu, ao liberar o porte de pequenas quantidades, desde que sejam para consumo próprio em lugares privados. $\mathrm{O}$ problema é que muitas pessoas são enquadradas como traficantes, mesmo portando pequenas quantidades de drogas (GALLASSI, 2015).

Ao se analisar a Bolívia e a Venezuela, importantes parceiros políticos do Brasil, verifica-se que, o porte de drogas para uso pessoal não é crime, mas o consumidor está sujeito a ser encaminhado para internação e tratamento, ou seja, o Estado é omisso na prevenção ao combate, mas é ativo no tratamento. Nesta análise há incertezas se os custos empregados nos tratamentos sobressaem às prevenções (GALLASSI, 2015).

Tem-se, ademais que, o Chile desde 2007, nove anos após a descriminalização das drogas, regulamentou-se a quantidade máxima permitida para a maconha, limitando a quantia a 10 gramas por cada usuário. O cultivo de até seis plantas também foi autorizado. Santiago do Chile, a capital do país, tem várias lojas de acessórios para quem quer cultivar a maconha em casa.

A Colômbia também têm suas peculiaridades no que se refere à política de drogas, por exemplo, quem carrega drogas para uso pessoal não pode ser preso desde 1994, no entanto, sinaliza uma fragilidade em um contexto remetido ao traficante, o que torna sua caracterização evidentemente mais difícil. Desta forma, após alguns anos, precisamente em 2009, fixou-se a quantidade permitida de cannabis em 20 gramas e a de cocaína em 1 grama.

Atualmente, a maioria dos países faz uso da maconha para fins medicinais, verificando-se, também, outros países com forte tendência a adotar esse posicionamento com a finalidade voltada para tratamentos médicos, a exemplo do Brasil dentre outros.

Países vizinhos ao Brasil que demonstram serem tolerantes ao uso de drogas é o Equador e o Paraguai, nesta conjuntura, o uso pessoal não é crime, no caso da maconha, a quantidade máxima para configurar uso pessoal é de 10 gramas e a de cocaína 2 gramas.

O Peru fortifica o rol de países favoráveis a uma política flexível ao uso de drogas ilícitas, embora o porte de drogas seja permitido há mais de dez anos, no entanto, os consumidores flagrados estão sujeitos a aguardarem em juízo decisões se caracterizam ou não tráfico (LEONARDO, 2015).

Há medidas governamentais que o Estado de direito deve programar, principalmente no que se refere à regulamentação de políticas antidrogas, incluindo-se o fortalecimento e acesso a diferentes profissões ou ocupações, que ultrapassam as fronteiras nacionais.

\subsection{POLÍTICA DE DROGAS NAS AMÉRICAS}


A responsabilidade da Américas como indutor do crescimento econômico e promotor da paz, da estabilidade e do desenvolvimento social na região é um marco da política externa, prevalecendo de forma imutável, um ambiente de intenso relacionamento amistoso com seus vizinhos (SANTOS, 2009).

Nos Estados Unidos da América a política de drogas muda de acordo com o Estado. É comum adotar-se posicionamento divergente de outro Estado, exemplo: Colorado, Washington, Oregon e Alasca, além de Washington, D.C. - a capital; que já legalizaram o consumo recreativo de maconha. Em outras regiões a erva é autorizada somente para fins medicinais.

Tem-se o país da Jamaica, vulgarmente conhecido como o país de Bob Marley, que em determinado contexto, faz menção às drogas, e autorizou o porte de até 55 gramas de maconha para uso pessoal e o plantio de cinco mudas, somando assim aos países adeptos ao uso de drogas.

No México, o uso pessoal também ostenta regulamentações governamentais, o porte de até 5 gramas de maconha, meio grama de cocaína, 50 miligramas de heroína ou uma pílula de ecstasy é considerado uso pessoal e não causa prisão. No entanto, após três apreensões o usuário tem que se submeter a tratamento, uma alternativa imposta, sobre pena de responder processualmente. Caso contrário, é processado.

Dentre os países considerados pioneiros no que se refere à legalização das drogas destacam-se os Países Baixos, que aderem ao posicionamento de uso pessoal de drogas, conhecidas como "coffee shops", onde a venda de maconha é permitida. O porte de até 5 gramas e o cultivo de até 5 pés também é aceito, assim como o consumo em público. O país também é famoso pela política de redução de danos, com fornecimento de agulhas e seringas descartáveis a viciados, em determinados pontos. Essa política de consumo em "coffee shops", atualmente é estendida aos turistas (SOARES, 2001).

Exemplo radical e pioneiro no que se refere à discriminação de drogas destaca Portugal, audacioso, ao descriminalizar largamente vários tipos de drogas, o que para muitos países se tornaria um problema de saúde pública. No entanto, os usuários deixaram de ser tratados como criminosos e passaram a ser considerados doentes. Quem for flagrado com até 25 gramas de maconha, 2 gramas de cocaína, 1 grama de heroína ou 1 grama de ecstasy é encaminhado a um comitê composto por médicos e assistentes sociais. Mas é possível responder criminalmente, desde que surpreendido por quantidades superiores à permitida.

Não diferente da politica apresentada por outros países europeus, a Constituição da Alemanha proíbe criminalizar a posse de pequenas quantidades de drogas. Os Estados alemães, porém, interpretaram a decisão de maneiras distintas, fazendo com que varie de acordo com a região do país, o que se aproxima da política dos EUA (MACRAE, 2003).

Existem certas circunstâncias que permitem aos Estados adotarem políticas e medidas diferenciadas, histórico que agrega costumes sociais e política local, impondo solução viável e remediável.

A Espanha soma-se aos países que defendem a descriminalização e o porte para uso pessoal, embora as pessoas flagradas estejam sujeitas a multas ou à suspensão da carteira de motorista, o que num primeiro momento é uma alternativa, mas que mostra uma contradição, com pontos jurídicos repressivos. São permitidas até 200 gramas de maconha, 7,5 de cocaína ou 3 de heroína. O cultivo de cannabis pode ser feito por membros de clubes, o que demanda uma análise mais acurada dos diversos fatores (SOARES, 2001). 
Nesse contexto, ressalte-se que o Estado tem um papel central nessa dinâmica econômica e jurídica, voltado para a construção de sua política no plano internacional, assim como no plano local (BIJOS, 2016). O estreitamento das relações se torna mais dinâmico, com políticas uniformes, em face das novas necessidades do país vizinho.

\section{CONCEITO DE ÉTICA E MORAL EM UMA ANÁLISE DESCENTRALIZADORA}

O debate em torno da ética remota à antiguidade, e fazia parte da rotina da cidade e da vida dos cidadãos, primando-se pelas qualidades de um homem bom, que se preocupa com sua comunidade. A preocupação de todos é a segurança de sua comunidade, esta comunidade é estabelecida graças à constituição, cada um executando bem a tarefa inerente à sua função, primando pela excelência (ARISTÓTELES, 1988). O comportamento esperado de cada pessoa, de cada governante, cada empreendedor, se revelará no grau de negócios praticados na comunidade, formando uma miríade de normas éticas e morais.

No que se refere à moral, pelo fato de serem responsáveis por construir o caráter dos cidadãos, evitando-se os abusos de bebidas alcoólicas, assim como de drogas. Esses alicerces constitucionais vão nortear a política de descriminalização de drogas ilícitas, ou direcioná-la a uma completa proibição. A perspectiva ética teórica perpassa por um viés religioso, que pode determinar a conduta ou a orientação de um cidadao, ou de um profissional. A perspectiva ética adotada por uma pessoa pode influenciá-la a agir de determinada maneira, mas vamos nos surpreender com a pluralidade de valores numa sociedade democrática (SCHÜKLENK, 2005). O que se constata é, na maioria das vezes, uma considerável falta de reflexão sobre as práticas adotadas, em especial quando se confronta uma série de conceitos divergentes, principalmente no que concerne às drogas ilícitas.

Segundo o Dicionário Aurélio (2005), a ética é o "estudo dos juízos de apreciação referentes à conduta humana suscetível de qualificação do ponto de vista do bem e do mal, seja relativamente a determinada sociedade, seja de modo absoluto". A ética vem da conduta, do próprio ser humano, do que se aprende em casa; ou seja, ser ético seria fazer o certo mesmo que não haja ninguém para vangloriar-se e por motivo plausível e justo. "A moral é um conjunto de normas, aceitas livre e conscientemente, que regulam o comportamento individual e social dos homens" (SANCHEZ, 2003).

Segundo Vásquez (2003, p. 69) "a função social da moral consiste na regulamentação das relações entre os homens (entre os indivíduos e entre o indivíduo e a comunidade) para contribuir no sentido de manter e garantir uma determinada ordem social (RIBEIRO, 2000)".

Percebe-se que a evolução humana somada a uma cultura de diversidade obriga a atualização das leis e dos costumes. Há, no entanto, uma notória preocupação dos operadores do direito, dos agentes policiais e dos educadores em abrir espaços para a descriminalização das drogas, que podem desvirtuar a vida de crianças e adolescentes.

Tanto a ética quanto a moral são responsáveis por construir os alicerces que vão nortear a conduta do homem, definindo seu caráter e virtudes, e ensinar como ele poderá se comportar em sociedade. Logo, a moral possui um caráter social que envolve comportamento moral dos indivíduos e grupos sociais, cujos atos têm caráter coletivo, porém livre e consciente. Mesmos os atos sendo individuais de uma forma ou de outra acabam afetando ao próximo, e por isso se torna objeto de reprovação ou aprovação. 
Crimes e criminosos, é certo, constituíram-se, de alguma forma, como parte relevante da historia da humanidade. Foram alvo de repressão, punição, controle, assim o advento da Criminologia, que se debruça sobre os aspectos não-legais do crime, suas causas, suas correlações e sua prevenção, e os contornos de enfermidades, vícios e loucura.

Nesse sentido, ainda é precoce o conhecimento dos riscos da descriminalização dessas substâncias psicoativas. Os legisladores, psicólogos e médicos, analisam com prudência o comportamento dos indivíduos, e os benefícios e malefícios das drogas ilícitas. Torna-se necessário agir com prudência, e analisar cada um dos países que já legalizaram as drogas, a fim de comparar, confrontar e verificar os novos paradigmas da comercialização das drogas ilícitas.

Por alterar o nível de consciência, o uso pode levar a práticas arriscadas, como sexo sem preservativo ou compartilhamento de seringas e outros materiais que podem transmitir o HIV/AIDS e a hepatite, ampliando o nível de vulnerabilidade das pessoas e investimentos cada vez maior na saúde pública ${ }^{2}$.

Desta forma, é recomentado ter resistência à legalização de Drogas Ilícitas. Diversos fatores deverão ser mantidos, entre elas forças policiais. Certo que outras drogas com características diferentes e com efeitos mais severos ao ser humano serão surgidas ao passo que devemos influenciar países do mesmo eixo a optarem por decisão nacional e não sermos submetidos a aceitar políticas de países vizinhos.

\section{REFERÊNCIAS}

ARISTÓTELES. Política (trad. Mário da Gama Kury). 2a Edição, Brasília: Editora UnB, 1988.

ASSOCIAÇÃO Brasileira de Estudos do Álcool e outras Drogas- ABEAD. O Impacto das Drogas na Sociedade Brasileira: busca de soluções. 2006. Disponível em: <http://www.antidrogas.com.br/mostrasosvida.php?c=52>. Acesso em: 15 jan. 2017.

BRASIL. Agência Nacional de Vigilância Sanitária. ANVISA. Anvisa Inclui 21

Substâncias em Lista de Drogas Proibidas, 2014. Disponível em: <http://portal.anvisa.gov.br> Acesso em: 18 jan. 2017.

BRASIL. Agência Nacional de Vigilância Sanitária. Portaria n. ${ }^{\circ}$ 344, de 12 de maio de 1998. Disponível em: < http://www.anvisa.gov.br/hotsite/talidomida/legis/portaria_344_98.pdf>. Acesso: 25 abril 2017.

BIJOS, Leila. Finanças públicas e intervenção estatal no Japão. Revista de Direito Econômico e Socioambiental, [s.1.], v. 7, n. 740, p.39-76, jan. 2016. Pontifícia Universidade Católica do Paraná - PUCPR.

http://dx.doi.org/10.7213/rev.dir.econ.socioambienta.07.001.ao03.

\footnotetext{
${ }^{2}$ NAÇÕES UNIDAS: Escritório Sobre Drogas e Crime. O Relatório Mundial Sobre Drogas 2009. Anti Drogas. Disponível em: < http://www.antidrogas.com.br/ind_unodc.php.> Acesso em: 06 abril 2017.
} 
BIJOS, Leila. Responsabilidade Social do Brasil: Processos de Integração. Revista de Direito Internacional Econômico e Tributário, [s.1.], v. 5, n. 1, p.25-68, 30 jun. 2010. Revista de Direito Internacional Econômico e Tributário. http://dx.doi.org/10.18838/2318-8529/rdiet.v5n1p25-68.

CRUZ, Elaine Patrícia. Artigos e Notícias sobre Dependência Química, 2016. Vida e Saúde. Disponível em: <http://www.lemavidaesaude.com.br/Noticias-alcooldrogas.html>. Acesso em: 14 jan. 2017.

CONSUMO de Drogas no Brasil Aumentou, G1 notícias. 15 set. 2015. Diz ONU, 2007. Disponível em: < http://g1.globo.com/Noticias/Brasil/.> Acesso em: 20 jan. 2017.

DINO, Alessandra; MAIEROVITCH, Wálter Fanganiello. Novas Tendências da Criminalidade Transnacional Criminosa. São Paulo: Editora UNESP, 2010.

FERREIRA, Aurélio Buarque de Holanda. Dicionário Aurélio. Curitiba/PR: Editora Positivo, 2010.

GALLASSI, A. D. et al. Custos dos problemas causados pelo abuso do álcool. In: Revista de Psiquiatria Clínica. v. 3. n. 12, p 15 - 40, 2015. Suplem. 2008.

GONZÁLEZ, Cecilia. Todo lo que necesitás saber sobre Narcotráfico. $1^{\text {a }}$. Ed., Buenos Aires: Paidós, 2015, p. 18.

KISSINGER, Henry. A diplomacia das grandes potências. $3^{\text {a }}$. ed., Rio de Janeiro: Francisco Alves, 2001.

LARANJEIRAS, R. et al.; Usuários de Substâncias Psicoativas: Abordagem, Diagnóstico e Tratamento. 2. ed. São Paulo: Conselho Regional de Medicina do Estado de São Paulo/ Associação Médica Brasileira, 2003.

LEONARDO, S. MARCELO, S. Conheça os Países onde o Porte de Drogas Não é Crime. 2015. Folha Uol. Disponível em: < http://www1.folha.uol.com.br/asmais/2015/09/1671352-conheca-os-paises-onde-oporte-de-drogas-e-liberado-para-uso-pessoal.shtml > Acesso em: 13 abr. 2017.

MACRAE, Edward. Aspectos Socioculturais do Uso de Drogas e Políticas de Redução de Danos .2003. Neip. Disponível em: < http://www.neip.info/downloads/edward2.pdf.> Acesso em: 18 abril 2017.

MILZA, Pierre. Les relations internationales de 1918 a 1939. $10^{\text {a }}$ Ed., Paris: Armand Colin., 1998. 192 p.

NAÇÕES UNIDAS: Escritório Sobre Drogas e Crime. O Relatório Mundial Sobre Drogas 2009. Anti Drogas. Disponível em: < http://www.antidrogas.com.br/ind_unodc.php.> Acesso em: 06 dez. 2016. 
NEUMAM, Camila. Novas Drogas Sintéticas. 09 jun. 2008. Uol. Disponível em: < http://noticias.uol.com.br/saude/ultimas-noticias/redacao.htm >. Acesso 16 out. 2016.

RIBEIRO, Edilma Felix. Ética e Moral e Sua Influencia na Sociedade. 200, Estudo Administração. Disponível em: <http://www.estudoadministracao.com.br/ler/16-112014-como-fazer-citacoes-internet/>. Acesso em: 07 nov. 2016.

\section{SOARES, Marcelo. Conheça os Países Onde o Porte de Drogas Para Uso Pessoal}

Não é Crime. 2001, Uol. Disponível em:<

http://www1.folha.uol.com.br/asmais/2015/09/1671352-conheca-os-paises-onde-oporte-de-drogas-e-liberado-para-uso-pessoal.shtml> Acesso em: nov. de 2016.

SANTOS, G. A. O. Drogas, Subjetividade e Cidadania: Sobre a Cidadania dos Usuários de Drogas Não Legais. Jornal do Psicólogo. n.95, ano 26, 2010, CRP-Mg. Disponível em: <http://www.catolicaonline.com.br/revistadacatolica2/artigosn4v2/34-pos-grad.pdf $>$. Acesso em: 02 set. 2016.

SANTOS, Eduardo dos. América do Sul, palestra apresentada na IV Conferência Nacional de Política Externa e Política Internacional, 3 e 4 de dezembro de 2009, organizada pela Fundação Alexandre de Gusmão e seu Instituto de Pesquisa de Relações Internacionais (texto acadêmico), p. 1.

SCHÜKLENK, Udo. Introdução à Ética na Pesquisa. In: Ética na Pesquisa (org. Debora Diniz; Dirce Guilhem; Udo Schüklenk). Brasília: Editora UnB, 2005, pp. 31-44.

SOARES, J ; O. C ; V. D . O Uso do Álcool Entre Estudantes do Ensino Médio e Universitários. (UFPR), Cogitare Enfermagem . v. 16, p. 154-161, 2011. Disponível em: < http://www.scielo.br/pdf/csp/v27n8/16.pdf>. Acesso em: 16 set 2016.

SANCHEZ, Adolfo. Ética. 24. ed. Rio de Janeiro: Civilização Brasileira, 2003.

VALENCIA, L. Drogas, conflito e os EUA: A Colômbia no Início do Século. Estudos Avançados. n. 55. v.19. São Paulo, 2005.

VARGAS D; DUARTE, Fernando Augusto Bicudo. Centros de Atenção Psicossocial em Álcool e Drogas (caps ad). A Formação e a Busca Pelo Conhecimento Específico da Àrea. Texto \& Contexto. v. 20, pp. 119-126, 2011.

VÁSQUEZ, Adolfo Sanchez. Ética. Rio de Janeiro: Civilização Brasileira, 2000: 61-82. (Capítulo III A essência da moral).

VIDALE, Giulia. Chá de Ayahuasca Pode, sim, Causar Psicose e até Matar. 10 mar. 2016. Veja. Disponível em:

http://veja.abril.com.br/saude/cha-de-ayahuasca-pode-sim-causar-psicose-e-ate-matar/. Acesso em: 11 nov. 2016. 